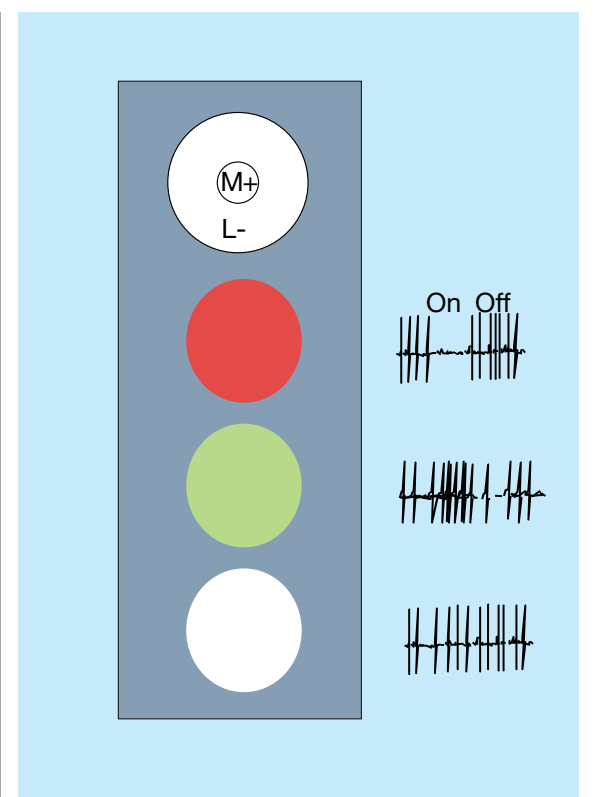

Figure 2 Colour opponency and a typical type I receptive field. Here, light of medium wavelength impinging on the centre of the receptive field excites the cell $(M+)$, whereas long-wavelength input to the surround inhibits it (L-). These colour-opponent signals are essential to colour perception. In this case the responses (the traces on the right) show that the cell would be excited by green light, inhibited by red light and relatively unaffected by white light.

to colour falls off in a way that is consistent with a random wiring between bipolar cells and retinal ganglion cells ${ }^{6}$. So it has been assumed that the midget ganglion cells fail to preserve the colour opponency of their bipolar cell inputs. But when Martin et al. ${ }^{1}$ directly measured the colour opponency of midget ganglion cells they found that more than half of those in the intermediate zone of peripheral retina (lying $20^{\circ}$ to $50^{\circ}$ from the central retina) are just as strongly colour opponent as those in the centre.

Martin etal. argue that the elliptical shape of the receptive-field centres in midget ganglion cells (they have an aspect ratio of about 1.8 ) is probably related to their colour selectivity. They show that a ganglion cell that receives input from all the bipolar cells in an appropriately oriented elliptical area can be highly colour selective (Fig. 3b). So the elliptical receptive-field centres could be the product of an adaptive developmental process that has selected bipolar cells driven by the same class of photoreceptor for each ganglion cell. One way to test this would be to examine ganglion cells in monkeys that had been reared in monochromatic light, which would block any selection process based on differential responses to colours.

Martin and colleagues' result ${ }^{1}$ is neat and embarrassing. The discrepancy between the physiological result and human psychophysics cannot be ignored because Martin et al. confirmed the psychophysical result in a

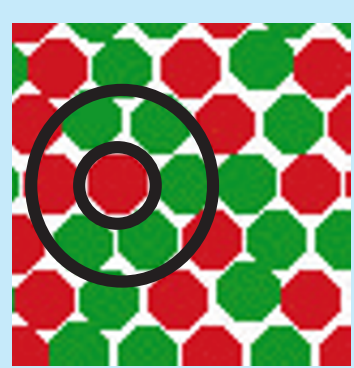

b

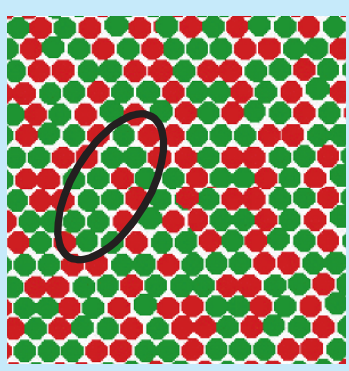

Figure 3 Colour opponency in the centre and periphery of the retina. a, A midget ganglion cell whose centre is driven by a single cone, as happens in the central retina, is almost guaranteed to have colour opponency. b, Martin et al. ${ }^{1}$ propose that the same effect can be achieved in the near periphery $\left(20^{\circ}\right.$ to $50^{\circ}$ from the centre) if the centre of the receptive field is elliptical and oriented so that most of its input comes from a single class of cone.

humans using the same stimuli that they had used for the physiology. There are two possible ways out, neither of which is very palatable. One is that, during processing of visual signals in the brain, there is a failure to use the information provided by colour-opponent ganglion cells in the near periphery of the retina. But this would introduce a problem for psychophysicists because they infer the properties of the visual system from measurements of visual performance. The other is that monkey and human retinas may be different, which again would be a tough conclusion to reach because the monkey has always been taken as a close physiological model for human vision. These doubts can be resolved only with data - either from psychophysical measurements on the periphery of monkey retinas, or from physiological work on the human retina. Andrew Derrington is in the School of Psychology,

University of Nottingham, University Park,

Nottingham NG7 2RD, UK.

e-mail: andrew.derrington@nottingham.ac.uk

1. Martin, P. R., Lee, B. B., White, A. J. R., Solomon, S. G. \& Rüttiger, L. Nature 410, 933-936 (2001).

2. Wiesel, T. N. \& Hubel, D. H. J. Neurophysiol. 29, 1115-1156 (1966)

Boycott, B. B. \& Dowling, J. E. Phil. Trans. R. Soc. Lond. B 225, 109-184 (1969)

4. Lennie, P., Haake, P. W. \& Williams, D. R. in Computational Models of Visual Processing (eds Landy, M. S. \& Movshon, J. A.) 71-82 (MIT Press, Cambridge, MA, 1991).

Wässle, H. et al. Vision Res. 34, 561-579 (1994).

6. Mullen, K. T. \& Kingdom, F. A. A. Vision Res. 36, 1995-2000 (1996)

Calkins, D. J. \& Sterling, P. Neuron 24, 313-321 (1999).
Daedalus

\section{Adhesive vapours}

Paper, felt and many other useful materials are made by wetting a mass of fine fibres or particles and letting them dry out. As they do so, surface tension forces the particles together. They adhere strongly when they are dry. Sadly, they tend to disintegrate again in the wet.

Curiously though, even dry particles can stick together by aqueous surface tension. Glass beads, for example, adhere weakly but spontaneously by the capillary condensation of a tiny amount of atmospheric humidity at their points of contact. Daedalus sees this as a route to a whole new range of aggregated materials. He recalls that methyl cyanoacrylate (superglue) is volatile, but polymerizes only in the liquid state. So he is exposing compact masses of cellulose fibres or plaster crystals to an atmosphere not quite saturated with cyanoacrylate vapour. It will condense by capillarity only at their points of contact. The liquid will then set, aggregating the particles with the absolute minimum of glue, applied exactly where it is needed. The resulting solid will be far stronger than ordinary plaster or paper, and will be waterproof.

Almost any combination of powders or fibres could be aggregated in this way. New composites of chalk, sawdust, soot, cotton fibres, iron filings and straw, or mixtures of these, should be possible, combining cheapness with many unexpected virtues. Non-woven fabrics, paper made from silica fibres or fine wire strands, porous diatomaceous concrete, wonderfully light synthetic eiderdown fluff, all seem possible.

But Daedalus wants to extend the idea to metals, as a sort of vapour-phase soldering. Imagine, he says, an electrical circuit unit with all the leads in place, touching the right components or contacts but not soldered to them. Expose the whole thing to unsaturated metal vapour: lead, tin or even mercury. Capillary condensation would condense it exactly at all the points of contact, making all the connections perfectly. Mercury would rapidly amalgamate with the metal it had condensed on, giving a stable non-volatile joint.

At present, microchips are often wired to their carriers by human operators using microscopes and micromanipulators. Vapour-phase capillary-condensation soldering could do the job automatically, at great speed, and with no need for precise manipulation. And nanotechnology would have a whole new method of microfabrication.

David Jones 